\title{
sciendo
}

\section{DIETARY SUPPLEMENTATION WITH NATURAL EXTRACTS MIXTURE: EFFECTS ON REPRODUCTIVE PERFORMANCES, BLOOD BIOCHEMICAL AND ANTIOXIDANT PARAMETERS IN RABBIT DOES}

\author{
Francesco Vizzarri ${ }^{1 *}$, Sara Chiapparini² ${ }^{2}$ Carlo Corino ${ }^{2}$, Donato Casamassima ${ }^{3}$, Marisa Palazzo ${ }^{3}$, \\ Vladimir Parkanyi ${ }^{4}$, Lubomir Ondruska ${ }^{4}$, Raffaella Rossi $^{2}$ \\ ${ }^{1}$ Department of Agricultural and Environmental Science, University of Bari Aldo Moro, \\ Via G. Amendola, 165/A 70126 Bari, Italy \\ ${ }^{2}$ Department of Health, Animal Science and Food Safety, Università degli Studi di Milano, \\ Via Celoria 10, 20133 Milan, Italy \\ ${ }^{3}$ Department of Agricultural, Environmental and Food Sciences, Università degli Studi del Molise, \\ Via Francesco De Sanctis, 1, 86100 Campobasso, Italy \\ ${ }^{4}$ National Agricultural and Food Centre Nitra, Hlohovecká 2, 95141 Lužianky, Slovak Republic \\ •Corresponding author: francesco.vizzarri@uniba.it
}

\begin{abstract}
The present study evaluates the effects of natural extracts on reproductive performance, haematochemical parameters, and antioxidant status of rabbit does. A total of sixty New Zealand White second parity does were divided into three groups: the first group was fed a control diet (CON), the second (T1) and the third groups (T2) were fed the same diet supplemented with prebiotic polysaccharides from brown seaweeds (Laminaria spp.) plus phenolic acid, hydroxycinnamic acids, tannins, and flavonoids from plant extracts $(0.3 \%$ and $0.6 \%$, respectively). The trial was conducted for two consecutive reproductive cycles (75 days). Reproductive performance was recorded. Blood samples were collected before the first insemination, $10 \mathrm{~d}$ after the first kindling, and $10 \mathrm{~d}$ after the second one. At the first reproductive cycle, productive parameters were negatively affected $(\mathrm{P}<\mathbf{0 . 0 5})$ by a high dosage of the dietary supplement ( $\mathrm{T} 2$ group). At the second reproductive cycle, no differences $(\mathrm{P}>\mathbf{0 . 0 5})$ between dietary treatments on reproductive and productive performances were observed. Bilirubin was affected by dietary treatment $(P<0.001)$ and decreased in relation to sampling time $(\mathrm{P}<\mathbf{0 . 0 0 1})$. The HDL cholesterol decreased by dietary treatment $(\mathrm{P}<0.01)$. All the plasma antioxidant markers were positively affected $(\mathrm{P}<0.001)$ by dietary supplementation and sampling time. No previous study has reported the effects of brown seaweeds and polyphenols on rabbit does and the present data shows that this natural extract supplement improved the antioxidant status of rabbit does.
\end{abstract}

Key words: rabbit, natural extract, blood, antioxidant markers

There has been increasing global concern regarding the development of antimicrobial resistance and the transfer of resistance genes from animal to human strains 
(Devirgiliis et al., 2013). Due to the ban on using antibiotic growth promoters in animal feed (1831/2003/EC EU), natural alternatives to support animal health and performance have been studied (Lillehoj et al., 2018). Phytogenic and plant extracts are an effective strategy to support a sustainable animal production (Pastorelli et al., 2012; Yang et al., 2015; Casamassima et al., 2014; Attia et al., 2017 a, b; ValenzuelaGrijalva et al., 2017; Attia et al., 2018). Brown seaweeds are an excellent source of vitamins and minerals (Descamps, 2006). They also contain sulfur polysaccharides, phlorotannin, catechins, carotenoids, tocopherols and diterpenes, which are characterized by antimicrobial, antioxidant, antinflammatory, and immunomodulatory activities (Maghin et al., 2014). These properties make these compounds promising in livestock as they improve animal health and welfare. As reviewed by Makkar et al. (2016) dietary supplementation with brown seaweed in rabbits has been shown to have different effects. In particular, dietary Laminaria spp. appears to improve the blood lipid profile, however Ascophillum nodosum supplementation should be avoided because it was shown to have a toxic effect. Previous studies have reported that tannins, a heterogeneous group of polyphenols, show antibacterial and antioxidant activities (Huang et al., 2018).

Rabbit production is based on a high reproductive efficiency, growth rate, feed utilization and meat nutritional parameters (Djakalia et al., 2012). Enteric pathologies are one of the main causes of mortality (Grilli et al., 2006). Natural extract supplementation could thus enhance rabbit doe health and performance during pregnancy and lactation. These phases are critical in does and are characterized by several physiological changes and an increase in the production of reactive oxygen species (Abdel-Khalek et al., 2008). The number of weaned rabbits needs to increase to enhance the does' productive performance, and nutrition has been largely recognized as a key factor in pregnancy and lactation phases (Chavatte-Palmer et al., 2016). The productive performance of does thus needs to be improved using sustainable dietary supplements (Okab et al., 2013; Casamassima et al., 2017; Uhlirova and Volek, 2019). Having focused attention on the animal welfare and the full expression of their productivity, the present study aims to evaluate the effects of dietary natural supplementation with a brown seaweed and polyphenol extract mixture on reproductive performance, biochemical parameters, and antioxidant markers of New Zealand White rabbit does.

\section{Material and methods}

\section{Animals and experimental design}

Does were handled following the guidelines for animal experiments, indicated in EU Directive 2010/63/EU, and national guidelines for the care and use of animals were followed. All experimental procedures involving animals were approved by an ethical committee (No. NPPC 18-10-2016).

The trial was performed from January to May 2017 in the experimental rabbit farm at the National Agricultural and Food Centre (Nitra, Slovak Republic). Second parity New Zealand White does $(n=60)$ were enrolled for two consecutive repro- 
ductive cycles (75 days). Lactating does were artificially inseminated at 12 days after kindling. Fourteen days after artificial insemination, the does were tested for pregnancy by palpation, and non-pregnant does were discarded from the experiment.

Does were individually housed in wire cages arranged in flat-decks measuring $600 \times 500 \times 330 \mathrm{~mm}$ high on one level. Cages were equipped with a hopper for feed and an automatic nipple drinking system. A lighting cycle of $16 \mathrm{~h}$ of light and $8 \mathrm{~h}$ of dark was used throughout the trial. Heating and forced ventilation systems maintained the building temperature within $18 \pm 4^{\circ} \mathrm{C}$. Relative humidity was about $70 \pm 5 \%$.

Table 1. Ingredients and chemical composition of experimental diets $(\mathrm{g} / \mathrm{kg})$

\begin{tabular}{|c|c|c|c|}
\hline \multirow{2}{*}{ Ingredients } & \multicolumn{3}{|c|}{ Experimental diet ${ }^{1}$} \\
\hline & $\mathrm{CON}$ & $\mathrm{T} 1$ & $\mathrm{~T} 2$ \\
\hline Maize & 282 & 279 & 276 \\
\hline Alfalfa hay & 305 & 305 & 305 \\
\hline Sunflower meal & 135 & 135 & 135 \\
\hline Palm seed oil & 8 & 8 & 8 \\
\hline Soybean oil & 7 & 7 & 7 \\
\hline Wheat & 80 & 80 & 80 \\
\hline Cane molasses & 20 & 20 & 20 \\
\hline Carob bean meal & 90 & 90 & 90 \\
\hline Oat & 53 & 53 & 53 \\
\hline Calcium carbonate & 7 & 7 & 7 \\
\hline Sodium Chloride & 3 & 3 & 3 \\
\hline Dicalcium phosphate & 2 & 2 & 2 \\
\hline DL-Methionine (99\%) & 2.5 & 2.5 & 2.5 \\
\hline L-Lysine $\mathrm{HCl}(78.5 \%)$ & 1.6 & 1.6 & 1.6 \\
\hline Choline $(75 \%)$ & 1.4 & 1.4 & 1.4 \\
\hline Vitamin and mineral premix ${ }^{*}$ & 2.5 & 2.5 & 2.5 \\
\hline Dietary supplement & 0 & 3 & 6 \\
\hline \multicolumn{4}{|l|}{ Chemical composition ${ }^{2}$} \\
\hline Crude protein & 184 & 183.6 & 183.5 \\
\hline Ether extract & 35.7 & 35.5 & 35.5 \\
\hline Crude fibre & 187 & 186.8 & 187 \\
\hline Ash & 86 & 85.7 & 85.8 \\
\hline Nitrogen free extract & 507 & 507.1 & 506.9 \\
\hline $\mathrm{NDF}$ & 302.1 & 301.5 & 301.7 \\
\hline $\mathrm{ADF}$ & 195.8 & 195.4 & 195.3 \\
\hline $\mathrm{ADL}$ & 39.9 & 39.5 & 39.5 \\
\hline
\end{tabular}

${ }^{1} \mathrm{CON}=$ control group; $\mathrm{T} 1=$ group supplemented with $0.3 \%$ of brown seaweed and plant polyphenols; $\mathrm{T} 2=$ group supplemented with $0.6 \%$ of brown seaweed and plant polyphenols;

"supplied per kg diet: 13,500 I.U. vitamin A (trans-retinyl acetate); 800 I.U. vitamin D3 (cholecalciferol); $35 \mathrm{mg}$ vitamin E (a-tocopherol min 91\%), $35 \mathrm{mg}$ copper (cupric sulphate pentahydrate).

${ }^{2}$ analyses determined in triplicate. 
For an adaptation period of one week, does were fed a commercial diet and the insemination was at the beginning of the trial, in which does were randomly assigned to one of three experimental groups $(n=20$ replicates per treatment) homogeneous for body weight $(4.83 \pm 0.19 \mathrm{~kg}$ ) and parity order (second). The first group (CON) received a control diet, and groups $\mathrm{T} 1$ and $\mathrm{T} 2$ received the same diet supplemented with $0.3 \%$ and $0.6 \%$ of a natural feed additive consisting of prebiotic polysaccharides from brown seaweeds (Laminaria spp.) plus phenolic acid, hydroxycinnamic acids, tannins, and flavonoids from plant extracts. The diets did not include anticoccidials, antibiotics or any other medications. The two dosages of the natural extract were chosen after an in vitro evaluation of the minimal inhibitory concentration (MIC) against Clostridium spp., Staphylococcus spp. and Escherichia coli spp. (Tosi, personal communication). The ingredients and the chemical composition of the experimental diets are reported in Table 1. The chemical composition of the experimental diet and the natural brown seaweeds and the polyphenol extract mixture was performed in accordance with the methods of the Association of Analytical Chemists (AOAC, 2000). The quantitative analysis of the phenolic compounds of the dietary plant supplement was performed by HPLC-UV-DAD (Russo et al., 2017). The chemical and phenolic compositions of the feed supplement are reported in Table 2. Does were fed ad libitum, and the average daily feed intake (ADFI) of the does was recorded. The body weight of the does was recorded the days before insemination.

Table 2. Chemical composition and polyphenols content of the dietary supplement

\begin{tabular}{|c|c|}
\hline Item $^{1}$ & $\%$ on dry matter \\
\hline Dry matter & $93.58 \pm 5.05$ \\
\hline Crude protein & $7.21 \pm 0.99$ \\
\hline Ether extract & $0.32 \pm 0.01$ \\
\hline Carbohydrates & $60.84 \pm 3.18$ \\
\hline Ash & $32.68 \pm 1.38$ \\
\hline \multicolumn{2}{|l|}{ Compounds, $\mathrm{mg} / \mathrm{kg}$ dry weight } \\
\hline \multicolumn{2}{|l|}{ Phenolic acid: } \\
\hline Dihydroxybenzoic acid & $\leq \mathrm{LOD} 2$ \\
\hline Syringic acid & $1059.79 \pm 62.82$ \\
\hline \multicolumn{2}{|l|}{ Hydroxycinnamic acids: } \\
\hline Neochlorogenic acid & $7979.23 \pm 468.11$ \\
\hline Rosmarinic acid & $126.54 \pm 8.67$ \\
\hline Trans sinapic acid & $105.54 \pm 8.09$ \\
\hline Chlorogenic acid & $21.45 \pm 3.65$ \\
\hline \multicolumn{2}{|l|}{ Tannins: } \\
\hline Ellagic acid & $2440.88 \pm 148.29$ \\
\hline Rutin & $272.37 \pm 20.82$ \\
\hline \multicolumn{2}{|l|}{ Flavonoids: } \\
\hline Myricetin & $53.88 \pm 5.68$ \\
\hline Kaempferol & $\leq \mathrm{LOD}$ \\
\hline
\end{tabular}

${ }^{1}$ values are expressed as means $(n=4) \pm$ standard deviation.

${ }^{2}$ limit of detection. 


\section{Reproductive performance}

Cross-fostering was applied within groups with a maximum of eight offspring/ litter. The number of offspring born alive and stillborn, the number of weaned offspring per litter, and the body weight of offspring at birth and at weaning per doe were recorded for two reproductive cycles ( 75 days).

\section{Blood sampling}

The first blood sampling was performed after $12 \mathrm{~h}$ fasting, at the beginning of the dietary supplementation ( $\mathrm{t} 0$ ). After two days, the rabbit does were artificially inseminated. The second blood sampling was performed 10 days after the first kindling (t1). The third blood sampling ( $\mathrm{t} 2$ ) was performed 10 days after the second kindling. Blood samples were taken from the vena auricolaris marginalis and were collected in $5 \mathrm{~mL}$ vacutainer glass tubes (Venoject ${ }^{\circledR}$, Terumo Europe N.V., Leuven, Belgium) with lithium heparin. The blood samples were immediately stored at $4{ }^{\circ} \mathrm{C}$. All blood analyses were performed at the laboratory of Animal Physiology Department at the Slovak University of Agriculture in Nitra, Slovak Republic, where samples were then centrifuged for $20 \mathrm{~min}$ at $3000 \mathrm{rpm}$ at $4^{\circ} \mathrm{C}$ to obtain plasma.

\section{Biochemical parameters}

Triglycerides, total cholesterol, HDL cholesterol and LDL cholesterol, bilirubin, alanine aminotransferase (ALT), aspartate aminotransferase (AST), were determined in plasma using a semi-automatic clinical chemistry Analyzer Arco model (Biotechnical Instruments, S.p.A., Italy).

\section{Plasma oxidative markers}

The superoxide dismutase (SOD) was determined using a colorimetric assay (Zhou and Prognon, 2006). The SOD activity was expressed in units per milligram of protein $(\mathrm{U} / \mathrm{mg})$.

The ferric ion reducing antioxidant power (FRAP) test was determined using the Benzie and Strain (1996) method, which measures the antioxidant capacity of plasma. One unit FRAP is expressed in $\mathrm{mmol} / \mathrm{mL}$ and indicates the number of moles of ferric ion (FeIII) reduced to ferrous ion (FeII) from one mol of tested antioxidant.

The total antioxidant status (TAS) was measured on blood plasma by 2,2'-azinobis (3-ethylbenzothiazoline-6-sulfonate) (ABTS) radical cation decolorization assay, following Re et al. (1999). Trolox was used as the standard. The TAS value of the samples was defined as the concentration of Trolox with an equivalent activity as units per liter of plasma.

The determination of thiobarbituric acid reactive substances (TBARS) was spectrophotometrically performed according to Esterbauer and Zollner (1989), using a standard curve with 1,1,3,3-tetra-methoxypropane (Sigma Aldrich, St. Louis, USA). The results were expressed as $\mathrm{mg}$ of malondialdehyde (MDA)/mL of plasma.

Vitamins A and E were extracted from plasma samples with chloroform, according to Zhao et al. (2004). The amount of vitamins was detected by HPLC (Kontron Instruments, Italy), which consisted of an automatic auto-sampler (HPLC Au- 
tosampler 360) with a loop of $20 \mu$, pump system (HPLC Pump 422), a column C18, $5 \mu \mathrm{m}, 250 \times 4.60 \mathrm{~mm}$, (Phenomenex, Torrance, Ca, USA). The mobile phase consisted of a mixture of acetonitrile and methanol $(85: 15 \mathrm{v} / \mathrm{v})$ with a flow value of $1 \mathrm{~mL} / \mathrm{min}$. Vitamins A and $\mathrm{E}$ were identified by comparing the retention time of the samples with the retention time of pure standards ( $>97 \%)$ purchased from Sigma Aldrich (St. Louis, USA). The quantification was performed using the Gyminix system (version 1.8.1) by comparing the peak of the area with that of the reference standard curve. Results were expressed as $\mathrm{mg} / \mathrm{mL}$ of plasma.

\section{Statistical analyses}

Statistical analyses of the data were performed using SPSS (SPSS/24 PC Statistics 24.0 IBM). After assessing whether the frequency distribution assumed normality with the Shapiro-Wilk Test, data on reproductive performances were analyzed by one-way analysis of variance (ANOVA) to evaluate the effects of dietary treatments at first and second partum. Data on biochemical parameters and antioxidant status were submitted to repeated-measures ANOVA to assess the main effects of treatment and time and their interaction. Rabbit does were considered as the experimental unit for all parameters. Data were reported as means \pm pooled SEM. Differences were considered statistically significant at a level of $\mathrm{P}<0.05$.

\section{Results}

\section{Productive and reproductive parameters}

During the experimental trial, $30 \%$ of does in the CON and T1 groups and 35\% in the T2 group were removed from the experiment due to lack of occurring pregnancy after artificial insemination and the data were removed from the analyses. No differences in body weight of the does at the second and third inseminations were observed $(\mathrm{P}>0.05)$. The average feed intake of does during pregnancy and lactation was not affected $(\mathrm{P}>0.05)$ by the dietary treatment. During pregnancy, the average daily feed intake was $318 \pm 8.5 \mathrm{~g}$ in the CON group, and $314 \pm 8.7 \mathrm{~g}$ and $320 \pm 9.7 \mathrm{~g}$ in groups T1 and T2 respectively. During lactation the average daily feed intake was $364 \pm 7.5 \mathrm{~g}$ in CON group and $395 \pm 9.9 \mathrm{~g}$ and $395 \pm 10.6 \mathrm{~g}$ in groups T1 and T2 respectively.

Tables 3 and 4 report the reproductive parameters of rabbit does evaluated at the first and second kindling cycle, respectively. The dietary treatments did not influence $(\mathrm{P}>0.05)$ the number of kits per litter, the mortality and weight of kits at birth and weaning in the first reproductive cycle. Although there was a difference in the number of offspring after the cross-fostering and at 14 days of lactation (lower number in $\mathrm{T} 2$ than in $\mathrm{CON}$ and $\mathrm{T} 1 ; \mathrm{P}<0.05)$ there was a greater mortality and a lower weight of the animals in $\mathrm{T} 2$ at weaning, although not significant. At weaning (35 days) the number of offspring per litter tended to be lower $(\mathrm{P}=0.055)$ in $\mathrm{T} 2$ than in the other groups. 
Table 3. Productive parameters at first reproductive cycle of rabbit does fed control diet (CON) and diets supplemented with two levels of brown seaweed and plant polyphenols $(0.3 \%$ and $0.6 \%$ in $\mathrm{T} 1$ and T2 groups respectively)

\begin{tabular}{|c|c|c|c|c|c|}
\hline \multirow{2}{*}{ Item $^{1}$} & \multicolumn{3}{|c|}{ Diet } & \multirow{2}{*}{ SEM } & \multirow{2}{*}{ P-value } \\
\hline & $\mathrm{CON}$ & $\mathrm{T} 1$ & $\mathrm{~T} 2$ & & \\
\hline \multicolumn{6}{|l|}{ Number of offspring per litter: } \\
\hline total born & 10.38 & 9.47 & 9.93 & 0.463 & 0.732 \\
\hline born alive & 9.81 & 9.07 & 9.40 & 0.487 & 0.827 \\
\hline born dead & 0.56 & 0.40 & 0.53 & 0.203 & 0.944 \\
\hline after cross-fostering & $7.73 \mathrm{a}$ & $7.94 \mathrm{a}$ & $7.13 \mathrm{~b}$ & 0.128 & 0.021 \\
\hline 14 days of lactation & $7.60 \mathrm{a}$ & $7.63 \mathrm{a}$ & $6.69 \mathrm{~b}$ & 0.189 & 0.022 \\
\hline 35 days (weaning) & 7.27 & 7.31 & 6.25 & 0.220 & 0.055 \\
\hline Dead, no. & 0.47 & 0.63 & 0.88 & 0.126 & 0.425 \\
\hline Mortality during lactation (\%) & 6.05 & 7.94 & 12.35 & 2.04 & 0.187 \\
\hline \multicolumn{6}{|l|}{ Weight of the litter $(\mathrm{kg})$} \\
\hline after cross-fostering & 0.596 & 0.514 & 0.557 & 0.028 & 0.508 \\
\hline 14 days & 2.17 & 2.12 & 1.81 & 0.099 & 0.072 \\
\hline 35 days (weaning) & 6.08 & 6.03 & 5.08 & 2.202 & 0.073 \\
\hline \multicolumn{6}{|l|}{ Weight of offspring (g) } \\
\hline birth & 64.67 & 58.00 & 59.33 & 1.75 & 0.264 \\
\hline weaning & 841.9 & 820.7 & 810.9 & 12.92 & 0.676 \\
\hline $\mathrm{ADG}^{2}(\mathrm{~g} / \mathrm{d})$ & 22.10 & 21.55 & 21.03 & 0.410 & 0.580 \\
\hline
\end{tabular}

${ }^{1}$ data are reported as mean \pm pooled standard error of means.

$\mathrm{a}, \mathrm{b}$ - within the same row, means with different letters differ significantly $(\mathrm{P}<0.05)$.

${ }^{2}$ average daily gain.

Table 4. Productive parameters at second reproductive cycle of rabbit does fed control diet (CON) and diets supplemented with two levels of brown seaweed and plant polyphenols $(0.3 \%$ and $0.6 \%$ in $\mathrm{T} 1$ and T2 groups respectively)

\begin{tabular}{|c|c|c|c|c|c|}
\hline \multirow{2}{*}{ Item $^{1}$} & \multicolumn{3}{|c|}{ Diet } & \multirow{2}{*}{ SEM } & \multirow{2}{*}{ P-value } \\
\hline & $\mathrm{CON}$ & $\mathrm{T} 1$ & $\mathrm{~T} 2$ & & \\
\hline \multicolumn{6}{|l|}{ Number of offspring per litter: } \\
\hline total born & 8.31 & 8.64 & 9.46 & 0.504 & 0.648 \\
\hline born alive & 7.85 & 8.00 & 8.77 & 0.477 & 0.714 \\
\hline born dead & 0.46 & 0.64 & 0.69 & 0.133 & 0.771 \\
\hline after cross-fostering & 7.00 & 7.14 & 7.08 & 0.169 & 0.943 \\
\hline 14 days of lactation & 6.93 & 7.00 & 7.08 & 0.189 & 0.942 \\
\hline 35 days (weaning) & 6.71 & 7.00 & 6.85 & 0.162 & 0.776 \\
\hline Dead, no. & 0.29 & 0.14 & 0.23 & 0.082 & 0.777 \\
\hline Mortality during lactation (\%) & 4.14 & 1.97 & 3.25 & 1.030 & 0.775 \\
\hline \multicolumn{6}{|l|}{ Weight of litter $(\mathrm{kg})$} \\
\hline Birth & 0.523 & 0.475 & 0.500 & 0.023 & 0.704 \\
\hline 14 days & 2.02 & 1.97 & 2.08 & 0.702 & 0.824 \\
\hline 35 days (weaning) & 7.28 & 7.12 & 6.94 & 0.203 & 0.798 \\
\hline \multicolumn{6}{|l|}{ Weight of offspring (g) } \\
\hline birth & 66.15 & 62.14 & 60.00 & 2.32 & 0.164 \\
\hline weaning & 1075 & 1028 & 1015 & 18.49 & 0.381 \\
\hline $\mathrm{ADG}^{2}(\mathrm{~g} / \mathrm{d})$ & 28.72 & 27.44 & 27.22 & 0.515 & 0.447 \\
\hline
\end{tabular}

${ }^{1}$ data are reported as mean \pm pooled standard error of means.

${ }^{2}$ average daily gain. 


\section{Biochemical parameters}

Table 5 shows the data on the does' plasma biochemical parameters in relation to dietary treatments and sampling time. Bilirubin values were affected by dietary treatments $(\mathrm{P}<0.01)$ and decreased in relation to sampling time $(\mathrm{P}<0.001)$. Comparing dietary treatments at the last sampling, bilirubin values were lower $(\mathrm{P}<0.05)$ in $\mathrm{T} 2$ than in $\mathrm{T} 1$ and $\mathrm{CON}$ rabbit does.

Table 5. Blood values of rabbit does fed control diet (CON) and diets supplemented with two levels of brown seaweed and plant polyphenols $(0.3 \%$ and $0.6 \%$ in $\mathrm{T} 1$ and $\mathrm{T} 2$ groups respectively) in relation to sampling time

\begin{tabular}{|c|c|c|c|c|c|c|c|}
\hline \multirow{2}{*}{ Item $^{1}$} & \multicolumn{3}{|c|}{ Diet } & \multirow{2}{*}{ SEM } & \multicolumn{3}{|c|}{ P-value ${ }^{3}$} \\
\hline & $\mathrm{CON}$ & $\mathrm{T} 1$ & $\mathrm{~T} 2$ & & $\mathrm{D}$ & $\mathrm{T}$ & $* \mathrm{D}$ \\
\hline \multicolumn{8}{|l|}{ Bilirubin (mg/dL) } \\
\hline $\mathrm{t} 0^{2}$ & 0.72 & 0.72 & 0.71 & 0.011 & & & \\
\hline $\mathrm{t} 1$ & 0.64 & 0.63 & 0.57 & 0.014 & & & \\
\hline $\mathrm{t} 2$ & 0.66 & 0.55 & 0.46 & 0.017 & $<0.001$ & $<0.001$ & $<0.001$ \\
\hline \multicolumn{8}{|c|}{ Triglycerides (mg/dL) } \\
\hline t0 & 66.43 & 64.03 & 67.96 & 1.165 & & & \\
\hline $\mathrm{t} 1$ & 65.44 & 60.47 & 63.82 & 0.977 & & & \\
\hline $\mathrm{t} 2$ & 63.44 & 59.86 & 63.03 & 1.139 & 0.195 & $<0.001$ & 0.753 \\
\hline \multicolumn{8}{|c|}{ Total cholesterol (mg/dL) } \\
\hline t0 & 56.68 & 54.69 & 53.15 & 0.727 & & & \\
\hline $\mathrm{t} 1$ & 55.28 & 54.14 & 51.16 & 0.904 & & & \\
\hline $\mathrm{t} 2$ & 57.79 & 53.43 & 53.17 & 0.873 & 0.072 & 0.103 & 0.333 \\
\hline \multicolumn{8}{|c|}{ LDL cholesterol (mg/dL) } \\
\hline t0 & 35.91 & 35.36 & 37.34 & 0.624 & & & \\
\hline $\mathrm{t} 1$ & 36.72 & 34.65 & 36.75 & 0.650 & & & \\
\hline $\mathrm{t} 2$ & 36.43 & 34.18 & 37.97 & 0.674 & 0.145 & 0.957 & 0.537 \\
\hline \multicolumn{8}{|c|}{ HDL cholesterol (mg/dL) } \\
\hline t0 & 31.50 & 33.47 & 31.15 & 0.714 & & & \\
\hline $\mathrm{t} 1$ & 29.58 & 36.80 & 32.69 & 0.732 & & & \\
\hline $\mathrm{t} 2$ & 30.03 & 36.00 & 32.80 & 0.896 & 0.005 & 0.311 & 0.039 \\
\hline \multicolumn{8}{|c|}{ Aspartate aminotransferase (UI/L) } \\
\hline t0 & 26.90 & 25.14 & 25.11 & 0.589 & & & \\
\hline $\mathrm{t} 1$ & 27.42 & 24.55 & 27.77 & 0.554 & & & \\
\hline $\mathrm{t} 2$ & 27.30 & 26.38 & 27.20 & 0.424 & 0.134 & 0.116 & 0.199 \\
\hline \multicolumn{8}{|c|}{ Alanine aminotransferase (UI/L) } \\
\hline t0 & 41.60 & 38.82 & 43.61 & 0.857 & & & \\
\hline $\mathrm{t} 1$ & 40.56 & 40.28 & 42.71 & 0.779 & & & \\
\hline t2 & 41.37 & 41.56 & 40.07 & 0.892 & 0.574 & 0.886 & 0.009 \\
\hline
\end{tabular}

${ }^{1}$ data are reported as mean values \pm pooled standard error of means.

${ }^{2} \mathrm{t} 0$, beginning of the dietary supplementation; $\mathrm{t} 1,10$ days after the first kindling; $\mathrm{t} 210$ days after the second kindling.

${ }^{3} \mathrm{D}=$-fixed effect of dietary supplementation; $\mathrm{T}=$ fixed effect of time; $\mathrm{D} \times \mathrm{T}=$ interaction dietary supplementation $\times$ time. 
An increase $(\mathrm{P}=0.005)$ in HDL cholesterol was observed in $\mathrm{T} 1$ at the second and third sampling times. No other biochemical parameters were affected $(\mathrm{P}>0.05)$ by dietary supplementation. Triglyceride values decreased in relation to sampling time $(\mathrm{P}<0.001)$. No other parameters were affected by dietary treatments or sampling time.

\section{Plasma antioxidant markers}

The plasma antioxidant status of does in relation to dietary treatment and sampling time is reported in Table 6 . All the parameters were affected by dietary treatments and sampling time $(\mathrm{P}<0.001)$. An interaction between time and treatment effects was also observed $(\mathrm{P}<0.01)$. The antioxidant parameters SOD, FRAP and TAS were higher $(\mathrm{P}<0.001)$ in groups fed seaweed and the polyphenol mixture and increased in relation to sampling time $(\mathrm{P}<0.001)$. Vitamins $\mathrm{A}$ and $\mathrm{E}$ increased significantly in $\mathrm{T} 1$ and $\mathrm{T} 2$ and in relation to sampling time $(\mathrm{P}<0.001)$. The MDA decreased in relation to sampling time in groups fed the natural feed supplement $(\mathrm{P}<0.001)$.

Table 6. Plasma antioxidant markers* of rabbit does fed control diet (CON) and diets supplemented with two levels of brown seaweed and plant polyphenols $(0.3 \%$ and $0.6 \%$ in $\mathrm{T} 1$ and $\mathrm{T} 2$ groups respectively) in relation to sampling time

\begin{tabular}{|c|c|c|c|c|c|c|c|}
\hline \multirow{2}{*}{ Item $^{1}$} & \multicolumn{3}{|c|}{ Diet } & \multirow{2}{*}{ SEM } & \multicolumn{3}{|c|}{ P-value ${ }^{3}$} \\
\hline & $\mathrm{CON}$ & $\mathrm{T} 1$ & $\mathrm{~T} 2$ & & $\mathrm{D}$ & $\mathrm{T}$ & $\mathrm{T} * \mathrm{D}$ \\
\hline \multicolumn{8}{|c|}{ Superoxide dismutase (U/mg) } \\
\hline $\mathrm{t} 0^{2}$ & 41.57 & 41.41 & 41.94 & 0.177 & & & \\
\hline $\mathrm{t} 1$ & 41.60 & 40.13 & 44.93 & 0.306 & $<0.001$ & $<0.001$ & $<0.001$ \\
\hline $\mathrm{t} 2$ & 41.91 & 56.54 & 59.88 & 1.056 & & & \\
\hline \multicolumn{8}{|c|}{ FRAP $(\mu \mathrm{mol} \mathrm{Fe} 2+/ \mathrm{L})^{4}$} \\
\hline t0 & 365.70 & 367.30 & 381.74 & 1.339 & & & \\
\hline $\mathrm{t} 1$ & 360.90 & 448.95 & 464.05 & 6.516 & $<0.001$ & $<0.001$ & $<0.001$ \\
\hline $\mathrm{t} 2$ & 362.10 & 486.85 & 489.11 & 8.077 & & & \\
\hline \multicolumn{8}{|c|}{ Total antioxidant status (U/L) } \\
\hline t0 & 11.45 & 11.99 & 12.07 & 0.110 & & & \\
\hline $\mathrm{t} 1$ & 11.86 & 19.92 & 22.86 & 0.632 & $<0.001$ & $<0.001$ & 0.038 \\
\hline $\mathrm{t} 2$ & 11.82 & 20.59 & 23.18 & 0.654 & & & \\
\hline \multicolumn{8}{|c|}{ Malondialdehyde $(\mu \mathrm{g} / \mathrm{mL})$} \\
\hline t0 & 2.83 & 2.84 & 2.87 & 0.012 & & & \\
\hline $\mathrm{t} 1$ & 2.97 & 2.41 & 2.50 & 0.035 & $<0.001$ & $<0.001$ & $<0.001$ \\
\hline $\mathrm{t} 2$ & 3.01 & 2.11 & 2.16 & 0.056 & & & \\
\hline \multicolumn{8}{|l|}{$\operatorname{Vitamin} \mathrm{A}(\mu \mathrm{g} / \mathrm{mL})$} \\
\hline t0 & 0.32 & 0.32 & 0.34 & 0.006 & & & \\
\hline $\mathrm{t} 1$ & 0.31 & 0.34 & 0.38 & 0.006 & $<0.001$ & $<0.001$ & 0.003 \\
\hline t2 & $0.33 \mathrm{a}$ & 0.35 & 0.40 & 0.007 & & & \\
\hline \multicolumn{8}{|l|}{ Vitamin $E(\mu \mathrm{g} / \mathrm{mL})$} \\
\hline t0 & 1.65 & 1.71 & 1.71 & 0.008 & & & \\
\hline $\mathrm{t} 1$ & 1.69 & 1.95 & 2.04 & 0.022 & $<0.001$ & $<0.001$ & $<0.001$ \\
\hline $\mathrm{t} 2$ & 1.69 & 2.33 & 2.28 & 0.039 & & & \\
\hline
\end{tabular}

'data are reported as mean values \pm pooled standard error of means.

${ }^{2} \mathrm{t} 0$, beginning of the dietary supplementation; $\mathrm{t} 1,10$ days after the first kindling; $\mathrm{t} 2,10$ days after the second kindling.

${ }^{3} \mathrm{D}=$ fixed effect of dietary supplementation; $\mathrm{T}=$ fixed effect of time; $\mathrm{D} \times \mathrm{T}=$ interaction dietary supplementation $\times$ time.

${ }^{4}$ ferric ion reducing antioxidant power. 


\section{Discussion}

\section{Productive and reproductive parameters}

The lower number of offspring per litter in the T2 group, compared with the other two groups, could indicate an adverse effect of the high dosage of the natural extract. In fact, up to weaning, milk is the main feed of kits, and the number of kits in a litter is closely related to the does' milk production. In addition, the physiological mechanisms that regulate the milk secretion can be influenced by natural bioactive compounds (Albert-Puleo, 1980). It is possible that the high dosage of natural extracts negatively affected the milk production and resulted in a lower survival rate and weaning weight. However, in the second reproductive cycle, no effect of dietary supplementation with brown seaweed and polyphenols extract mixture was observed on the productive parameters, thus suggesting that tolerance increases with the advanced age of does. In the present experiment a high prebiotic activity from brown seaweeds was expected, however it is possible that the feed additive had no effects on productive and reproductive performance due to the good breeding conditions and low pathogen pressure (Attia et al., 2017 c). Thus, studies in field conditions are needed in order to validate the present data.

In a similar study on rabbit does, Okab et al. (2013) observed an improvement in kindling rate, litter size, and offspring ratio, after supplementation of $2 \%$ of brown seaweed. The authors linked the results with an enhancement in sexual receptivity, highlighting the positive correlation between fertility and prolificacy in artificially inseminated rabbits. The difference between our data and the literature could be related to the different feed supplement and length of the dietary supplementation.

\section{Biochemical parameters}

The feed additive decreased the bilirubin values in the plasma of does in the treated groups (T1 and T2), which could be related to the antioxidant activity of polyphenols. In fact, inflammatory and oxidative injuries can up-regulate the cellular antioxidant status by generating antioxidants such as bilirubin. The low bilirubin plasma concentration at the last sampling time could be indicative of a better defense against oxidative damage (Aliyu et al., 2007).

An increase in plasma HDL values in the supplemented groups was observed at the end of the trial. Brites et al. (2017) reported that the HDL values showed antioxidant and antiatherogenic activities that suggest it protects LDL from oxidation. The improved blood lipid profile may be related to the effects of polyphenols, which are involved in the regulation of lipid and glucose metabolism (Attia et al., 2018). According to some authors (Bursill and Roach, 2007), these bioactive compounds activate the PPAR- $\alpha$ receptor, with an increased stimulation effect in the liver of the expression of key proteins involved in the metabolism of HDL. Triglycerides also seem to be involved in the same mechanism of activation of PPAR- $\alpha$ by polyphenols, with an induction in lipoprotein lipase expression in peripheral tissues and increased lipolysis, however in our study, no dietary effect on the triglyceride content was observed. 
Our previous study on sheep, hares and piglets fed with polyphenols revealed a significant reduction in triglycerides, total cholesterol, and LDL cholesterol along with an increased HDL cholesterol (Corino et al., 2007; Palazzo et al., 2011; Casamassima et al., 2012). The present data suggest that natural extracts contain several hypocholesterolemic agents which might prove valuable for the modulation of lipid metabolism and prevention of cardiovascular diseases (Attia et al., 2018).

\section{Plasma antioxidant markers}

The dietary supplementation with the brown seaweed and plant polyphenol mixture improved the markers of plasma oxidative status. The bioactive compounds contained in the feed additive (phenolic acid, hydroxycinnamic acids, tannins and flavonoids) are redox-active molecules, and can be oxidised and reduced without becoming highly reactive-radical; thus, they protect against free radicals (Attia et al., 2018). A consequent reduction in lipid peroxidation was observed, as also highlighted by the improvement in the enzymatic marker levels. The reduction in lipid peroxidation could be related to the direct capture of free radicals due to the antioxidant activity of bioactive molecules during the propagation phase of the chain reaction. In addition, the initial oxidative process may be blocked through the inhibition of the pro-oxidant enzymes that produce free radicals (Kamiloglu et al., 2006). The increase in plasma liposoluble vitamins may also be attributed to the ability of the natural compounds to strengthen the endogenous antioxidant system. This is achieved by controlling the oxidative metabolism, by reducing the production of reactive oxygen radicals, and by inducing enzymes with antioxidant activities (Zhu et al., 1999). Comparable data have been obtained in previous studies on hares, naturally milk-fed lambs and ewes, all fed a diet supplemented with a natural extract rich in polyphenols (Palazzo et al., 2011; Casamassima et al., 2012, 2013). Also, in pigs (Rossi et al., 2013, 2017) and broilers (Attia et al., 2017 a; 2017 b; 2018), a dietary supplementation with natural extracts increased the blood antioxidant activity, which in pigs was measured with a biological KRL test.

\section{Conclusion}

Our data on the productive and reproductive performances suggest that the lower dosage of dietary supplement containing prebiotic polysaccharides from brown seaweeds (Laminaria spp.) plus phenolic acid, hydroxycinnamic acids, tannins, and flavonoids from plant extracts positively affect the antioxidant status of does without influencing other parameters. An environmentally-friendly dietary integration seems to be promising in supporting the does' health, by enhancing the antioxidant status. Further studies in field conditions are needed to evaluate the effects of feed supplements on rabbit does' zootechnical parameters and to explore the mechanism of action on gut health.

\section{Conflict of Interest}

The authors confirm that they have no conflict of interest. 


\section{Acknowledgments}

Authors would like to thank the technical staffs of the National Agricultural and Food Centre, Nitra (Slovak Republic) for the availability of rabbit does and technical support during the whole experimental period.

\section{Funding}

This work was supported by Department's funds of the University of Milan and University of Molise.

\section{References}

Abdel-Khalek A.M., Selim N.A., El-Medany Sha A., Nada S.A. (2008). Response of doe rabbits to dietary antioxidant vitamins $\mathrm{E}$ and $\mathrm{C}$ during pregnancy and lactation. Nutrition and Digestive Physiology. Proc. 9th World Rabbit Congress, Verona, Italy, pp. 519-524.

A 1 b e r t - P u le o M. (1980). Fennel and anise as estrogenic agents. J. Ethnopharmacol., 2: 337-44.

Aliyu R., Gatsing D., J a ry um K.H. (2007). The effects of Boswellia dalzielii (Burseraceae) aqueous bark extract on rat liver function. Asian J. Biochem., 2: 359-363.

AOAC (2000). Official methods of analysis (17th ed.). Gaithersburg, MD, Association of Analytical Communities.

A t $t$ i a Y.A., A l- H a r th i M.A., H a s s a S.S. (2017 a). Turmeric (Curcuma longa Linn.) as a phytogenic growth promoter alternative for antibiotic and comparable to mannan oligosaccharides for broiler chicks. Rev. Mex. Cienc. Pecu., 8: 11-21.

Attia Y.A., B akhashwain Ahmed A., Bertu Nehal K. (2017 b). Thyme oil (Thyme vulgaris L.) as a natural growth promoter for broiler chickens reared under hot climate. Ita J. Anim. Sci., 16: 275-282.

A t t i a Y.A., Hamed R.S., B overa F., Abd E1-Hamid A.E., A 1-Harthi M.A., Shahb a H.A. (2017 c). Semen quality, antioxidant status and reproductive performance of rabbits bucks fed milk thistle seeds and rosemary leaves. Anim. Reprod. Sci., 184: 178-186.

A t t i a Y.A., B a kh a s hw a in A.A., B e rtu N.K. (2018). Utilisation of thyme powder (Thyme vulgaris L.) as a growth promoter alternative to antibiotics for broiler chickens raised in a hot climate. Europ. Poult. Sci., 82, Doi: 10.1399/eps.2018.238

B e $\mathrm{n}$ z i e F.F., S tra in J.J. (1996). The ferric reducing ability of plasma (FRAP) as a measure of "antioxidant power": the FRAP assay. Anal. Biochem., 239: 70-76.

B rites F., Martin M., Guillas I., Kontush A. (2017). Antioxidative activity of high-density lipoprotein (HDL): Mechanistic insights into potential clinical benefit. BBA Clin., 8: 66-77.

B u r sill C., R o a c h P. (2007). A green tea catechin extract upregulates the hepatic low density lipoprotein receptor in rats. Lipids, 42: 621-627.

C a s a mas sim a D., P a lazzo M., Marte muc ci G., Vizzarri F., Corino C. (2012). Effects of verbascoside on plasma oxidative status and blood and milk production parameters during the peripartum period in Lacaune ewes. Small Rumin. Res., 105: 1-8.

Cas a massima D., Palazzo M., D' A less andro A.G., Colella G.E., Vizzarri F, Cor in o C. (2013). The effects of lemon verbena (Lippia citriodora) verbascoside on productive performance, plasma oxidative status, and some blood metabolites in suckling lambs. J. Anim. Feed Sci., 22: 204-212.

C a s a m a s i ma D., N ardo i a M., P a lazzo M., Vizzarri F., D ' A les s andro A.G., Cori n o C. (2014). Effect of dietary extruded linseed, verbascoside and vitamin E supplements on yield and quality of milk in Lacaune ewes. J. Dairy Res., 81: 485-493.

Casamassima D., Palazzo M., Vizzarri F., Ondruska L., Massanyi P., Corino C. (2017). Effect of dietary Lippia citriodora extract on reproductive and productive performance and plasma biochemical parameters in rabbit does. Anim. Prod. Sci., 57: 65-73. 
Chavat te-P a $1 \mathrm{~m}$ er P., Tarrade A., K i efer H., Duranthon V., J a m m e s H. (2016). Breeding animals for quality products: not only genetics. Reprod. Fert. Develop., 28: 94-111.

Corin o C., C a nn at a S., Mus e 11 a M., P a s tore 11 i G., R o s s i R. (2007). Influence of verbascoside on lipid profile in weaned piglets. Ann. Nutr. Metab., 51: 270.

Des camps V., Colin S., Lahaye M., Jam M., Richard C., Pot in P., B arbeyron T., Yvin J.C., K l o a re g B. (2006). Isolation and culture of a marine bacterium degrading the sulfated fucans from marine brown algae. Mar. Biotechnol., 8: 27-39.

Devirgili is C., Zinno P., Perozzi G. (2013). Update on antibiotic resistance in foodborne Lactobacillus and Lactococcus species. Front. Microbiol., 4: 301.

Djaka lia B., Gu ichard B.L., Fernande A.E. (2012). Effect of palm oil and soya bean oil on growth performance and health of rabbit before and after weaning. J. Appl. Anim. Res., 40: 56-62.

Esterbauer H., Z ollner H. (1989). Methods for determination of aldehydic lipid peroxidation products. Free Radical Bio. Med., 7: 197-203.

Grilli G., Ferrazzi V., Agnoletti F., P i c cirillo A., P is on i A.M., Gallazzi D. (2006). La patologia enterica nel coniglio da carne allevato in Italia. Rivista di Zootecnia e Veterinaria, 34: 51-56.

Huang Q., Liu X., Zha o G., Hu T., Wang Y. (2018). Potential and challenges of tannins as an alternative to in-feed antibiotics for farm animal production. Anim. Nutr., 4: 137-150.

Kamiloglu N.N., B e ytut E., Aksakal M. (2006). Alteration in antioxidant status and lipid peroxidation of sheep previously treated with vitamin $\mathrm{A}$ and $\beta$-carotene during breeding and periparturient period. B. Vet. I. Pulawy, 50: 171-177.

Lillehoj H., Liu Y., Calsamiglia S., Fernandez Miyakawa M.E., Chi F., Crave n s R.L., O h S., G a y G.C. (2018). Phytochemicals as antibiotic alternatives to promote growth and enhance host health. Vet. Res., 49: 76.

Maghin F., Ratti S., Corin o C. (2014). Biological functions and health promoting effects of brown seaweeds in swine nutrition. J. Dairy Vet. Anim. Res., 1: 14-16.

Makkar H.P.S., Tran G., H euzé V., Reverdin S.G., Les s ire M., L ebas F., Ankers P. (2016). Seaweeds for livestock diets: A review. Anim. Feed Sci. Technol., 212: 1-17.

Okab A.B., S a mara E.M., Abdoun K.A., Rafay J., Ondruska L., Parkanyi V., Pivko J., Ay o ub M.A., A 1 - Ha id ary A.A., A ljumaah R.S., P eter M., Lukac N. (2013). Effects of dietary seaweed (Ulva lactuca) supplementation on the reproductive performance of buck and doe rabbits. J. Appl. Anim. Res., 41: 347-355.

Palazzo M., Vizzarri F., Cinone M., Corino C., Cas a massima D. (2011). Assessment of a natural dietary extract titrated in phenylpropanoid glycosides, on blood parameters and plasma oxidative status in intensively reared Italian hares (Lepus corsicanus). Animal, 5: 844-850.

Pastorelli G., Rossi R., Corino C. (2012). Influence of Lippia citriodora verbascoside on growth performance, antioxidant status, and serum immunoglobulins content in piglets. Czech J. Anim. Sci., 57: 312-322.

R o s s i R., P a s t or e 11 i G., C or in o C. (2013). Application of KRL test to assess total antioxidant activity in pigs: sensitivity to dietary antioxidants. Res. Vet. Sci., 94: 372-377.

Ross i R., Stella S., Ratti S., Magh in F., Tirlon i E., Corino C. (2017). Effects of antioxidant mixtures in the diet of finishing pigs on the oxidative status and shelf life of Longissimus dorsi muscle packaged under modified atmosphere. J. Anim. Sci., 95: 4986-4997.

Rus s o R., Pucci L., Gi orgetti L., Árvay J., Vizzarri F., Longo V., Pozzo L. (2017). Polyphenolic characterisation of plant mixture (Lisosan ${ }^{\circledR}$ Reduction) and its hypocholesterolaemic effect in high fat diet-fed mice. Nat. Prod. Res., 33: 651-658.

Uhlíř o vá L., Volek Z. (2019). Effect of dehulled white lupine seeds on the milk production and milk composition in rabbit does and the growth performance of their litters before weaning. J. Anim. Feed Sci., 28: 291-297.

Valenzuela-Grijalva N.V., Pinelli-Saavedra A., Muhlia-Almazan A., Domínguez-Díaz D., González-Ríos H. (2017). Dietary inclusion effects of phytochemicals as growth promoters in animal production. J. Anim. Sci. Technol., 59: 8.

Yang C., Chow dhury M.A., H u o Y., Gong J. (2015). Phytogenic compounds as alternatives to in-feed antibiotics: potentials and challenges in application. Pathogens, 23: 137-56. 
Zhao B., Tham S.Y., Lu J., La i M.H., Le e L.K.H., Moochhala S.M. (2004). Simultaneous determination of vitamins $C, E$, and $\beta$ carotene in human plasma by high-performance liquid chromatography with photodiode-array detection. J. Pharm. Pharm. Sci., 7: 200-204.

Z h o u J.Y., Prog n on P. (2006). Raw material enzymatic activity determination: A specific case for validation and comparison of analytical methods - the example of superoxide dismutase (SOD). J. Pharmaceut. Biomed., 40: 1143-1148.

Zhu Q.Y., H u ang Y., Ts an g D., Chen Z.Y. (1999). Regeneration of $\alpha$-tocopherol in human low density lipoprotein by green tea catechin. J. Agr. Food Chem., 47: 2020-2025.

Received: 31 VII 2019

Accepted: 13 XI 2019 